\title{
Trabalhonecessário
}

\section{EDITORIAL: BRASIL, TIRA A POEIRA DOS PORÕES (OU, PARA ALÉM DA SOCIEDADE DO ESPETÁCULO) ${ }^{1}$}

Brasil, chegou a vez de ouvir as Marias, Mahins, Marielles e malês.

(Estação Primeira de Mangueira, 2019)

Difícil escrever um editorial sintonizado com a conjuntura, principalmente quando se trata de refletir sobre o que, em 1967, Guy Debord (1997) denominou de "sociedade do espetáculo". Escandalizado com a capacidade das sociedades modernas produzirem um arsenal de espetáculos que favorece "a inversão concreta da vida" (p.13), Debord afirma que a materialização da ideologia se manifesta como uma espécie de esquizofrenia, ou "um fato alucinatório social". (p.139). Sem desconsiderar as bases materiais de produção social da existência, e, portanto, o diálogo com o materialismo histórico, e em especial com a Ideologia Alemã, de Marx e Engels, o autor assegura que "a ideologia é a base do pensamento de uma sociedade de classes, no curso conflitante da história" (p.137).

Para Guy Debord, o êxito da ideologia materializada em forma de espetáculo, se deve ao êxito da "produção econômica autonomizada" (p. 137). Afirma ser necessário "emancipar-se das bases materiais da verdade invertida, eis no que consiste a auto emancipação de nossa época" (p.141). Na verdade, na $221^{\text {a }}$ e última tese, Debord tenta nos livrar da posição de meros espectadores da sociedade do espetáculo, indicando-nos a importância de "realizar a 'missão histórica de instaurar a verdade no mundo"' (p.141) e, portanto, de superar as determinações de homens e mulheres-de-negócio que cultuam o Deus Mercado e seus representantes no planeta Terra.

Crítico da sociedade de consumo, com discurso libertário e considerado por ele mesmo como 'doutor em nada', Debord faleceu em 1994. Se vivo estivesse, nos diria que, hoje, no Brasil e na América Latina incendeiam-nos milhares de notícias,

${ }^{1}$ DOI: https://doi.org/10.22409/tn.17i32.p28299 
revelações, fatos e fake news que se constituem como verdadeiros espetáculos legitimados "pela ditadura efetiva da ilusão" (p.137). Estendendo-se a todas as esferas da vida, "o espetáculo é a ideologia por excelência" (138), com capacidade de suprimir os "limites do verdadeiro e do falso", graças ao "recalcamento de toda a verdade vivida, diante da presença real da falsidade garantida pela organização da aparência" (p. 140).

Para milhares e milhares de latino-americanos e outros tantos da população planetária que acessam televisores e as mídias sociais, fica difícil (mas não impossível) perceber a forma como tem sido tratado, por exemplo, o "caso Venezuela", cuja população tem sido açoitada pelo boicote do império norteamericano, promovido por Donald Trump e seus asseclas, entre eles, Jair Bolsonaro que, em recente viagem a Washington, colocou a base de Alcântara a serviço dos EUA. Na verdade, a Constituição Brasileira de 1988 foi rasgada e, com ela o artigo 4ำ que afirma que as relações internacionais devem se pautar pelos princípios da soberania nacional, prevalência dos direitos humanos, autodeterminação dos povos, não-intervenção, igualdade entre os Estados, defesa da paz, solução pacífica dos conflitos, entre outros. E que, em seu parágrafo único, estabelece que o Brasil busque a integração econômica, política, social e cultural dos povos, visando a formação de uma comunidade latino-americana de nações.

Em Conspiração e estratégia, José Luís Fiori (2018) identifica quatro estratégias básicas utilizadas pelos Estados Unidos no sentido de intervir, de forma autoritária e com métodos rápidos e adequados, nos governos e regimes que the desagradem. A primeira, a mais antiga de todas, é intervir nos processos eleitorais. A novidade é que isto passou a ser feito com o desenvolvimento de técnicas eletrônicas que, adentrando nos domicílios privados dos cidadãos, corroboram para a manipulação do inconsciente coletivo, de maneira a criar uma "vontade eleitoral". No Brasil, a eleição de Jair Bolsonaro não foi diferente! Uma segunda estratégia diz respeito aos tradicionais "golpes militares" não apenas no período da Guerra Fria, mas que persistem, quando necessário, como no caso da Turquia, em 2016 e, agora, na Venezuela. Uma terceira estratégia são as sanções monetário-financeiras, que se transformam em arma mortal, provocando a queda do valor da moeda e o estrangulamento das atividades econômicas do país alvo. Por fim, a quarta estratégia são as chamadas 'guerras híbridas', na qual se usa mais a informação do 
que a força, capaz de produzir a desmoralização e a destruição da vontade política do adversário.

Podemos inferir que a compressão espaço-tempo, sinalizada por Harvey (1992), com a qual Guy Debord não conviveu plenamente, as redes/mídias sociais têm produzido o sentimento de que estamos bem informados e, ao mesmo tempo, pouco informados. A vida tem passado tão rápida que não sobra tempo para nos dar conta dos milhares de eventos que acontecem nos bastidores da política e da vida cotidiana de homens e mulheres da classe trabalhadora que, a cada dia, perdem os direitos sociais duramente conquistados. Sobre a Reforma Trabalhista (Lei o 13.467/2017) e o projeto de Reforma da Previdência (PEC no 6/2019), por exemplo, nosso atual presidente argumenta ser preciso escolher entre ter direitos e ter empregos (sic!).

Como parte da estratégia dos setores ultraconservadores, em nome da luta contra a corrupção e em nome de um Deus que está acima da Constituição e da laicidade do Estado, materializa-se na "sociedade do espetáculo" uma ideologia de cunho protofascista, necessária ao Estado de Exceção que se instalou depois da deposição da presidente Dilma Rousseff, em 2016 e da prisão de Luiz Inácio Lula da Silva, em 2018. Em março de 2019, assistimos à prisão e a soltura de Michel Temer, mesmo sabendo a justiça federal que o mesmo é chefe de quadrilha há mais de 40 anos.

Depois do vergonhoso episódio de Jesus na goiabeira, contado por Damares Alves, do Ministério da Mulher, da Família e dos Direitos Humanos, tivemos o descalabro de ouvir de lolene Lima, indicada para o MEC e demitida oito dias depois, que o ensino deverá ser baseado na palavra de Deus e que os componentes curriculares, em especial nos primeiros anos da educação básica, sigam a perspectiva do criacionismo, em detrimento da ciência. "O aluno vai aprender que 0 autor da História é Deus, o realizador da Geografia é Deus. Deus fez as planícies, o relevo, o clima. O primeiro matemático foi Deus" (Mariana Haubert, 22/03/19).

Mas não é só: há que se lembrar da triste ideia do Ministro da Educação, de espetacularizar imagens de crianças cantando o hino nacional, perfilados em frente à bandeira nacional, como parte "da política de incentivo à valorização dos símbolos nacionais", em estilo militarizado, de maneira a cultuar e inculcar a ideologia fascista, assim como a continência de Bolsonaro à bandeira americana, a influência dos 
militares e dos evangélicos em todas as esferas da administração pública. Todas estas ações fazem parte do espetáculo injusto e desumano de uma sociedade cujos dirigentes querem aprofundar as políticas neoliberais à custa da exploração sobremaneira dos seres humanos e da natureza.

Entre um espetáculo e outro, é (im)possível não perceber a delonga do processo de investigação da morte de Marielle Franco, cruelmente executada no dia 14 de março de 2018, junto com o motorista Anderson Gomes. Depois de presos os acusados da matança da vereadora do PSOL/RJ, fica a pergunta: afinal, quem mandou matar Marielle?

A vida passa! O carnaval/2019 passou! No espetaculoso desfile no Sambódromo chamou a atenção nacional e internacional o samba da Estação Primeira de Mangueira, vencedora do grupo especial da Liga das Escolas de Samba do Rio de Janeiro - Liesa. Mais que nunca, é hora de "tirar a poeira dos porões", assim dizia o samba-enredo "Histórias para ninar gente grande", cujo desfile terminou com o sorriso de Marielle estampado em uma enorme bandeira verde e rosa.

Além da história de Marielle, "é hora de contar a história que a história não conta”, a história de tamoios, mulatos, de mulheres negras guerreiras como Dandara dos Palmares e Luiza Mahin, ou como os Malês que lutaram por liberdade, liberdade esta que "não veio do céu nem das mãos de Isabel". De fato, "tem sangue retinto pisado, atrás do herói emoldurado", pois como sabemos, a história oficial não conta, "desde 1500 tem mais invasão do que descobrimento", e de fato, para a história oficial não são reconhecidos/as quem são os sujeitos que fazem a história. Sujeitos encarnados, datados e situados no mundo. Estas são algumas das denúncias e dos possíveis anúncios da Estação Primeira de Mangueira, para o contexto atual que vivemos.

Um belo espetáculo! Da Avenida Marquês de Sapucaí, no "abre alas para seus heróis de barracão", o tributo à Marielle Franco repercutiu no mundo inteiro. É "na luta que a gente se encontra"; assim, mais que nunca "chegou a vez de ouvir as Marias, Mahins, Marielles, malês”. São “verde e rosa as multidões”! Também são azul e branco, amarelo e preto, vermelho e branco e de todas as cores das escolas de samba e dos blocos carnavalescos do Brasil. 
Para desvelar o "avesso do mesmo lugar" na sua totalidade, precisamos compreender a "sociedade do espetáculo" na perspectiva de Guy Debord e, como indicam Pierre Dardot e Christian Laval (2016), considerar "a nova razão do mundo" que se plasma na sociedade neoliberal. Nos movimentos do real, captar a existência de outros "espetáculos" que a vida contraditoriamente nos oferece. Espetáculos coletivamente produzidos por homens e mulheres que lutam por processos de emancipação humana fundados na reprodução ampliada da vida, e não do capital.

Neste delicado momento histórico em que vivemos, nada mais oportuno do que trazer aos leitores da Revista Trabalho Necessário, um número temático dedicado à análise da pertinência das categorias fundantes do materialismo histórico dialético no século XXI. Em que medida os ensinamentos de Marx e da teoria marxista são capazes de nos ajudar a compreender e transformar o mundo? Organizado pelos Profs. Drs. Dante Moura (IFRN) e Ramon de Oliveira (UFPE), a TN 32 traz o debate ocorrido no IV Intercrítica, realizado em novembro de 2018, além de outras importantes contribuições do pensamento crítico em relação ao mundo do trabalho, à formação humana e as relações históricas entre trabalho e educação, conforme anuncia a linha editorial de nossa revista.

Boa leitura!

\section{Referências:}

Os editores

DARDOT, Pierre; LAVAL, Christian. A nova razão do mundo. Ensaio sobre a sociedade neoliberal. São Paulo: Boitempo, 2016.

DEBORD, Guy. Sociedade do espetáculo. Rio de Janeiro: Contraponto, 1997.

FIORI, José Luiz. Conspiração e estratégia. Sul 21, publicado em 22/02/2019. https://www.sul21.com.br/opiniaopublica/2019/02/conspiracao-e-estrategia-por-joseluis-fiori/

HARVEY, David. A condição pós-moderna: uma pesquisa sobre as origens da mudança na cultura. São Paulo: Edições Loyola, 1992.

HAUBERT, Mariana. Sem nem assumir, nova $\mathbf{n}^{\circ} \mathbf{2}$ diz que deixa MEC em meio à crise. https.//educação.uol.com.br/notícias/2019/03/22. Acessado em 24/03/2019. 